\title{
Corrigendum: Emotional Intelligence in Elementary School Children. EMOCINE, a Novel Assessment Test Based on the Interpretation of Cinema Scenes
}

\author{
Santiago Sastre ${ }^{1}$, Teresa Artola ${ }^{1}$ and Jesús M. Alvarado ${ }^{2 *}$ \\ ${ }^{1}$ University Center Villanueva, Complutense University of Madrid, Madrid, Spain, ${ }^{2}$ Department of Psychobiology \& Behavioral \\ Sciences Methods, Faculty of Psychology, Complutense University of Madrid, Madrid, Spain
}

Keywords: emotional intelligence, elementary children, test validity, films, emotional problems and disorders

\section{OPEN ACCESS}

Approved by:

Frontiers Editorial Office,

Frontiers Media SA, Switzerland

*Correspondence: Jesús M. Alvarado jmalvara@ucm.es

Specialty section: This article was submitted to

Developmental Psychology, a section of the journal

Frontiers in Psychology

Received: 19 August 2019

Accepted: 20 August 2019

Published: 11 September 2019

Citation:

Sastre S, Artola T and Alvarado JM (2019) Corrigendum: Emotional Intelligence in Elementary School

Children. EMOCINE, a Novel Assessment Test Based on the Interpretation of Cinema Scenes. Front. Psychol. 10:2031. doi: 10.3389/fpsyg.2019.02031

\section{A Corrigendum on}

Emotional Intelligence in Elementary School Children. EMOCINE, a Novel Assessment Test Based on the Interpretation of Cinema Scenes

by Sastre, S., Artola, T., and Alvarado, J. M. (2019). Front. Psychol. 10:1882. doi: $10.3389 /$ fpsyg.2019.01882

In the original article, there was a mistake in the legend for Figures 2, 3, and $\mathbf{4}$ as published. The legends were not included in the article. The correct legends appear below.

"Figure 2. Distribution of latent classes regarding behavior in school/classroom. Different letters $(a, b)$ indicate significant differences in sensitive responses".

"Figure 3. Sociogram results regarding latent classes. Different letters (a,b) indicate significant differences in sensitive responses".

"Figure 4. Emotional and behavioral problems from SENA questionnaire showing significant differences regarding latent classes".

Additionally, there was a mistake for the department in affiliation 2. The correct department is "Department of Psychobiology \& Behavioral Sciences Methods".

The authors apologize for this error and state that this does not change the scientific conclusions of the article in any way. The original article has been updated.

Copyright $\odot 2019$ Sastre, Artola and Alvarado. This is an open-access article distributed under the terms of the Creative Commons Attribution License (CC BY). The use, distribution or reproduction in other forums is permitted, provided the original author(s) and the copyright owner(s) are credited and that the original publication in this journal is cited, in accordance with accepted academic practice. No use, distribution or reproduction is permitted which does not comply with these terms. 